\title{
FORMAS DE RETORNO DA PESQUISA ETNOBOTÂNICA À COMUNIDADE NO PARADIGMA DA COMPLEXIDADE AMBIENTAL E EDUCAÇÃO AMBIENTAL
}

\author{
Mariana Martins da Costa Quinteiro \\ Ana Mayumi Gonçalves Tamashiro \\ Moemy Gomes de Moraes ${ }^{1}$
}

RESUMO: A Educação Ambiental (EA) vem sendo apontada como ferramenta de fundamental importância na aderência da sociedade moderna a novos paradigmas. Definir o ferramental metodológico para implementar a sustentabilidade é um grande desafio. Informações sobre o uso de recursos naturais por populações tradicionais têm oferecido modelos de uso sustentável. O objetivo deste trabalho é investigar a interface entre a Educação Ambiental e a Etnobotânica, pelo paradigma da complexidade ambiental, enfatizando a importância das perspectivas de retorno dos trabalhos para a comunidade. A Etnobotânica, abordada de forma mais complexa, pode fornecer subsídios para realização de ações em EA embasadas na realidade socioambiental e nas formas de cognição específicas das comunidades estudadas.

Palavras-chave: Desenvolvimento Sustentável; Etnociência; Comunidades Tradicionais

${ }^{1}$ Professora do Instituto de Ciências Biológicas, Universidade Federal de Goiás. E-mail: moemy@icb.ufg.br. 


\section{INTRODUÇÃO}

As questões ambientais vieram a suscitar nas sociedades a discussão das influências de vizinhanças, a avaliação suprafronteiriça de suas atitudes, decisões e procedimentos e a mudança de paradigmas: do paradigma social de uso infinito dos recursos para o novo paradigma do desenvolvimento sustentável (DIAS, 2000). Neste momento, a Educação como um todo e a Educação Ambiental, em particular, deverá desempenhar o importante e fundamental papel de promover e estimular a aderência das pessoas e da sociedade a esse novo paradigma.

Apesar da grande polêmica em torno do conceito e das estratégias de sustentabilidade, é consenso o prisma da multidimensionalidade dessa questão. Definir o ferramental metodológico para viabilizar e implementar a sustentabilidade é um grande desafio. A aplicação prática desses conceitos, principalmente no que se refere à sustentabilidade ecológica como base para conservação de recursos naturais renováveis, passa pela premissa do "manejo sustentável" (PAVAN-FRUEHAUF, 2000).

A acumulação de informações sobre uso de recursos naturais por populações tradicionais tem oferecido aos cientistas modelos de uso sustentável desses mesmos recursos (ALBUQUERQUE, 1997, 1999). Nesse aspecto, a Etnobotânica tem papel primordial, pois compreende o estudo das sociedades humanas, passadas e presentes e suas interações ecológicas, genéticas, evolutivas, simbólicas e culturais com as plantas (ALEXIADES, 1996).

Pesquisas nesta área facilitam a determinação de práticas apropriadas ao manejo da vegetação com finalidade utilitária, pois empregam os conhecimentos tradicionais obtidos para solucionar problemas comunitários ou para fins conservacionistas (FONSECA-KRUEL; PEIXOTO, 2004). Podem ainda subsidiar trabalhos sobre usos sustentáveis da biodiversidade através da valorização e do aproveitamento do conhecimento empírico das sociedades humanas, a partir da definição dos sistemas de manejo, incentivando a geração de conhecimentos científicos e tecnológicos voltados para o uso sustentável dos recursos naturais (FONSECA-KRUEL; PEIXOTO, 2004).

Albuquerque \& Lucena (2004) alertam que, se por um lado muitas técnicas, programas e formas de manejo têm sido sugeridos e alguns desenvolvidos com certo êxito, tradicionalmente, os etnobotânicos têm se ocupado mais em registrar as plantas, seus usos e formas terapêuticas (no caso das plantas medicinais) por populações humanas, deixando de lado as questões socioculturais. Os autores incentivam assim a associação do conhecimento tradicional ao desenvolvimento de estratégias coerentes com o desenvolvimento sustentável, pois assim seriam capazes de se integrarem no corpo das políticas públicas locais.

Se, durante a pesquisa etnobotânica forem considerados esses 
atingido para viabilidade das futuras gerações, é abordado e vivenciado no âmbito da Educação Ambiental, de forma transdisciplinar.

Nesse contexto, o objetivo deste trabalho é investigar a interface entre a Educação Ambiental e a Etnobotânica, pelo paradigma da complexidade ambiental, enfatizando a importância das perspectivas de retorno dos trabalhos para a comunidade. Assim, busca-se embasar reflexões sobre o tema, com benefícios tanto para os detentores do saber científico (estudantes, pesquisadores e educadores) como para os do saber popular, na construção de metodologias complexas, passíveis de serem incorporadas em políticas públicas locais.

\section{ETNOBOTÂNICA E EDUCAÇÃO AMBIENTAL (EA)}

A EA apresenta-se como uma dimensão do processo educativo voltada para participação de seus atores, educandos e educadores, na construção de um novo paradigma que contemple as aspirações populares de melhor qualidade de vida socioeconômica e um mundo ambientalmente sadio (GUIMARÃES, 1995).

Para Dias (2000), a EA deverá ser capaz de catalisar o desencadeamento de ações que permitam preparar os indivíduos e a sociedade para o paradigma do desenvolvimento sustentável, modelo estrategicamente adequado para responder aos desafios dessa nova ordem mundial. Trata-se da passagem no mundo euclidiano, cartesiano para uma nova construção: a complexidade sistêmica.

Entretanto, a retotalização do saber que reclama a problemática ambiental não é a soma nem a integração dos conhecimentos disciplinares tradicionais, que externalizam o ambiente; o saber ambiental requer uma problematização dos paradigmas do conhecimento, das práticas de pesquisa e das ideologias da teoria e da prática, isto é, requer ser pensado sob a perspectiva do paradigma da complexidade (LUZZI, 2003).

Morin (2006) igualmente alerta a necessidade de uma reforma paradigmática, definindo que o nível paradigmático é o núcleo forte que comanda todos os pensamentos, todas as ideias, todos os conhecimentos que se produzem sobre o seu império. $O$ autor acredita que o problema-chave é a formação de um pensamento complexo, que se esforça para unir ideias e para operar diferenciações.

Nesse sentido, o conhecimento empírico das pessoas que têm relação mais intensa com a natureza encontra-se como um dos alvos dessas questões. Assim a Etnobotânica destaca-se como uma das estratégias interessantes para o desenvolvimento de atividades de EA locais.

No contexto da investigação Etnobotânica, o pesquisador procura observar a rotina e a cosmogonia da comunidade pesquisada, se colocando como aprendiz e apto a trocar conhecimentos (PATZLAFF; PEIXOTO, 2009). Nesse contato, no entanto, mais que os inventários do uso de recursos

revista brasileira educação ambiental 
vegetais, a Etnobotânica possibilita a análise de aspectos socioculturais e de formas de cognição particulares das comunidades locais, fundamentais para incursões de ações em EA. Entretanto, a maior parte dos trabalhos científicos da área publicados no Brasil tem a forte tendência de ser apenas descritivos, baseados em lista de espécies (OLIVEIRA et al., 2009).

Considerando as características das pesquisas em Etnobotânica, percebe-se que oferecem a possibilidade do exercício da nova ciência complexa, apontada por Demo (1993), Guimarães (1995), Dias (2000), Luzzi (2003), Riojas (2003) e Morin (2006), entretanto cabe aos pesquisadores colocar em prática esses conceitos.

\section{A PESQUISA CIENTÍFICA E O RETORNO DOS TRABALHOS ETNOBOTÂNICOS}

Realizar a pesquisa que atenda aos interesses e demandas da sociedade é uma questão que deveria ser intrínseca às instituições de ensino superior. Pesquisa é questão de atitude processual cotidiana, devendo haver o encontro propício da qualidade formal e política, tornando a vida acadêmica mais educativa, científica e menos alienada (DEMO, 1993). A legitimidade retórica das instituições de ensino superior está em que se concebem a si mesmas como agentes que internalizam os problemas sociais e lhes oferecem soluções no campo do conhecimento e da formação de agentes de transformação social ou de serviço à sociedade (RIOJAS, 2003).

A Convenção da Diversidade Biológica (CDB) firmada em 1992 por 162 países, dentre eles o Brasil, determina que haja a repartição dos benefícios derivados da utilização dos recursos genéticos (CUNHA, 1999). Nesse contexto, a questão do retorno das pesquisas etnocientíficas às comunidades de onde partiram as informações ganhou destaque. Para Patzlaff e Peixoto (2009, s/p) "a questão do retorno, embora antiga, tomou força principalmente diante dos compromissos da sociedade com conservação, uso sustentável e repartição de benefícios derivados da utilização da biodiversidade, especialmente em países megadiversos, como o Brasil". Alexiades (1996) discute que esses estudos deveriam beneficiar de alguma forma as pessoas envolvidas, individualmente e/ou em comunidade, principalmente, quando há uso extensivo do tempo e da experiência das pessoas locais, sendo interessante a consulta do que e como retornar a elas.

Apesar dessas recomendações, a análise de artigos científicos em Etnobotânica revela pouquíssimos casos de retorno e aplicabilidade dessas pesquisas, o que deixa uma lacuna quanto a essa questão. Assim, durante a execução dos trabalhos pouco se ouve sobre as necessidades das comunidades locais, se propõe alternativas para a melhoria das condições socioambientais vigentes ou se explora outras formas cognitivas inerentes à utilização desses recursos vegetais. As tabelas 1 e 2 apresentam uma síntese do que foi obtido em trabalhos científicos a este respeito. 
Tabela 1: Alternativas de retorno e aplicabilidade de pesquisas etnobotânicas sugeridas e propostas.

\begin{tabular}{llll}
\hline Autores/ano & \multicolumn{2}{c}{$\begin{array}{c}\text { Atividades sugeridas e } \\
\text { propostas }\end{array}$} & \multicolumn{1}{c}{ Benefícios sugeridos } \\
\hline Cotton (1996) & Identificação de produtos vegetais & $\begin{array}{l}\text { Geração de fonte alternativa de renda para } \\
\text { comercializáveis. }\end{array}$ & $\begin{array}{l}\text { madeireiros e agricultores; uso sustentável } \\
\text { de espécies com potencial de }\end{array}$ \\
& & comercialização reconhecido.
\end{tabular}

Cotton (1996) Instrução da comunidade em estudo sobre atividades de ecoturismo, capazes de gerar fontes alternativas de renda, como hotéis, entretenimentos, trilhas, esportes e parques naturais.

Fonseca-Kruel Criação de espaços que possibilitem o e Peixoto compartilhamento do saber entre (2004) jovens e o segmento de mais idade da comunidade.

Fonseca-Kruel e Peixoto (2004)

Confecção de catálogo com as informações sobre as plantas, como produto final do trabalho, devolvido para população através de associação de moradores, administração da Unidade de Conservação (UC's) e/ou outras formas de organizações sociais.

Fonseca-Kruel Criação de Reservas Extrativistas.

e Peixoto

Viabilização e sustentabilidade econômica de projetos voltados para o desenvolvimento sustentável.

Conservação do conhecimento tradicional.

Valorização da cultura local; conhecimento das etnoespécies pelos gestores das UC's.

Aumento das atividades econômicas locais, concomitante à exploração sustentável dos recursos da região.

Manutenção e a valorização das tradições sobre o uso das plantas.

e Peixoto

Estabelecimento de hortos.

(2004)

Albuquerque e Lucena (2004)

Queiroz

(2005)
Convocação de uma reunião geral, em que seja mostrado todo o processo a ser desenvolvido na comunidade (dependências de uma escola ou associação rural).

Criação de Reservas de Desenvolvimento Sustentável.
Quinteiro (2008)
Criação de medidas e estímulo ao Manejo Florestal Comunitário, com estruturação de um horto-viveiro florestal.
Trocas entre a comunidade científica e a população local em geral.

Conservação da biodiversidade; manutenção das condições e meios necessários para a reprodução social; melhoria dos modos e da qualidade de vida por meio da exploração racional e sustentada dos recursos naturais por parte das populações tradicionais; valorização, conservação e aperfeiçoamento do conhecimento e técnicas de manejo do ambiente desenvolvido por estas populações.

Integrar objetivos sociais, econômicos e ambientais com a paisagem ecológica e cultural, produzindo uma diversidade de produtos tanto para consumo como para o mercado. 
Tabela 2: Alternativas de retorno e aplicabilidade de pesquisas etnobotânicas vivenciadas.

\begin{tabular}{|c|c|c|}
\hline Autores/ano & Atividades vivenciadas & Benefícios alcançados \\
\hline $\begin{array}{l}\text { Polezzi et al. } \\
(2004)\end{array}$ & $\begin{array}{l}\text { Promoção de intercâmbio Universidade-Escola- } \\
\text { Comunidade envolvendo o uso, cultivo e iden- } \\
\text { tificação de plantas medicinais na Vila de Per- } \\
\text { nambuco (MS); palestras e debates por profes- } \\
\text { sores e acadêmicos da Universidade Estadual } \\
\text { de Mato Grosso Sul, com alunos do ensino } \\
\text { médio e fundamental de uma escola da região. }\end{array}$ & $\begin{array}{l}\text { Trocas entre o saber científico e o } \\
\text { saber popular em geral. }\end{array}$ \\
\hline $\begin{array}{l}\text { Bortolotto e } \\
\text { Neto (2005) }\end{array}$ & $\begin{array}{l}\text { Desenvolvimento de atividades com alunos de } \\
\text { uma escola municipal em Corumbá (MS), no } \\
\text { beneficiamento de uma planta aquática nativa da } \\
\text { América do Sul, o Camalote (Eichhornia } \\
\text { crassipes (Mart.) Solms, Pontederiaceae). }\end{array}$ & $\begin{array}{l}\text { Geração de parte da fonte de renda } \\
\text { da população local; realização de } \\
\text { debates sobre a importância da } \\
\text { atividade para a comunidade, os } \\
\text { possíveis impactos ao meio } \\
\text { ambiente que estariam relacionados } \\
\text { com sua extração e sobre o uso } \\
\text { sustentável dos recursos. }\end{array}$ \\
\hline
\end{tabular}

Figueiredo et al. (2005)

Figueiredo et al. (2005) al. (2005)

\section{Fonseca-}

Kruel et al. (2006)

Pinto et al. (2006)
Figueiredo et

Elaboração de cartilha popular, abordando as principais plantas utilizadas na comunidade; a auto-medicação; cuidados com o cultivo, coleta e armazenamento das plantas medicinais; fabricação de remédios caseiros; precauções sobre 0 uso desses medicamentos; plantas tóxicas; indicações terapêuticas e efeitos colaterais dos vegetais.

Realização de oficinas e dinâmicas, na Universidade, na Unidade Básica de Saúde e nas Escolas Comunitárias de duas cidades de João Pessoa (PB).

Construção de programa na rádio comunitária local, intitulado "Fitoterapia na Comunidade", abordando assuntos sobre plantas medicinais, saúde e outras temáticas escolhidas de acordo com a necessidade local.

Elaboração de um manual com o resumo dos conhecimentos etnobotânicos de pescadores artesanais de Arraial do Cabo, Rio de Janeiro, abordando ainda percepções sobre meio ambiente, história e realidade social da região.

Criação de apostilas contendo informações populares e outras observações científicas, pesquisadas posteriormente.

Quinteiro

(2012)
Criação de horto-viveiro em escola, de mutirões de agrofloresta, distribuição de folhetos informativos sobre as espécies vegetais e promoção de saraus ambientais para revalorização da cultura local.
Trocas entre o saber científico e o saber popular em geral; valorização da cultura local conhecimento das etnoespécies pelos gestores das UC's.

Criação de espaço em que moradores locais puderam discutir e compartilhar seus conhecimentos sobre o uso das plantas medicinais; horizontalização de conhecimentos acadêmicos.

Divulgação das informações sobre plantas para um maior número de pessoas.

Trocas entre o saber científico e o saber popular em geral; valorização da cultura local conhecimento das etnoespécies pelos gestores das UC's.

Apresentação e distribuição das apostilas à equipe do Instituto de Estudos Sócio-Ambientais do Sul da Bahia (IESB), responsável pelos projetos desenvolvidos na área e às 26 famílias que participaram da pesquisa.

Trocas entre o saber científico e o saber popular em geral; valorização da cultura local; divulgação das etnoespécies e da agrofloresta para os turistas e a comunidade local; plantio de espécies nativas e cultivo de mudas nativas. 
As oportunidades encontradas nesses trabalhos tratam-se quase que exclusivamente de sugestões e propostas, não sendo apresentados seus resultados, características de sua aplicabilidade ou dificuldades e facilidades encontradas nessas aplicações.

Pela leitura e sistematização da bibliografia consultada, as comunidades-alvo de estudo das pesquisas etnobotânicas são peças-chave na obtenção de formas de manejo sustentado dos recursos vegetais e de diversas outras estratégias coerentes com o desenvolvimento sustentável local e, consequentemente, das ciências que estudam essas perspectivas etnoconservacionistas, devendo ser incluídas em programas de EA.

Entretanto, essa troca é praticamente unidirecional: pouco a ciência se preocupa em retornar os dados das pesquisas etnobotânicas às comunidades de onde primeiramente partiram essas informações. Dessa forma, as abordagens levantadas nesses estudos, principalmente se realizadas de maneira mais complexa, consistem em ferramentas valiosas para práticas locais em EA, adaptadas à realidade socioambiental e ao conjunto de valores das comunidades estudadas.

\section{CONSIDERAÇÕES FINAIS}

A atual demanda da sociedade no campo do ensino se dá por aprendizagens contínuas e complexas. É necessário um redimensionamento do campo educativo no sentido de interagir mais, e de forma coerente, com as realidades locais e globais e reproduzir menos os modelos vigentes.

A EA vem sendo apontada como uma dimensão do processo educativo envolvida na construção do novo paradigma do desenvolvimento sustentável. Entretanto, o saber ambiental necessário a essa reforma paradigmática requer a formação de um pensamento complexo.

A Etnobotânica, por possuir caráter interdisciplinar dentro e fora do espaço formal de ensino, privilegia ações de trocas entre a ciência e a sociedade, uma vez que o pesquisador, ao buscar o conhecimento empírico da população, tem grande potencial para realizar esse diálogo, compartilhando informações e conhecimentos. Entretanto, são poucos os trabalhos que propõe e programam medidas de retorno à sociedade.

As Etnociências podem acumular conhecimento específico e ao mesmo tempo serem usadas como ferramenta para a EA, resgatando e valorizando principalmente o conhecimento tradicional e local. Assim poderá, de forma direta ou indireta, levar a realização de práticas que se enquadram na lógica do desenvolvimento sustentável e da complexidade ambiental. 


\section{REFERÊNCIAS}

ALBUQUERQUE, U.P. Etnobotânica: uma aproximação teórica e epistemológica. Revista Brasileira de Farmácia. Rio de Janeiro, v.78, n.3, p.60-64, 1997.

ALBUQUERQUE, U.P. La importância de los estúdios etnobiológicos para estabelecimento de estratégias de manejo y conservación em las florestas tropicales. Biotemas. Florianópolis, v.12, n.1, p.31-47, 1999.

ALBUQUERQUE, U.P.; LUCENA, R.F.P. Métodos e técnicas na Pesquisa Etnobotânica. Recife, Livro rápido, 2004.

ALEXIADES, M. Selected guidelines for ethnobotanical research: a field manual. New York, New York Botanical Garden, 1996.

BORTOLOTTO, I.M.; NETO, G.G. O uso do camalote, Eichhornia crassipes (Mart.) Solms, Pontederiaceae, para confecção de artesanato no distrito de Albuquerque, Corumbá, MS, Brasil. Acta Botanica Brasilica. São Paulo, v.19, n.2, p.331-337, 2005.

COTTON, C.M. Ethnobotany: principles and applications. Chichester, Britsh Library, 1996.

CUNHA, M.C. Populações tradicionais e a Convenção da diversidade biológica. Estudos Avançados. São Paulo, v.13, n.36, p.147-163, 1999.

DEMO, P. Desafios modernos da educação. $2^{a}$ ed. Petrópolis, Vozes, 1993.

DIAS, G.F. Fundamentos da Educação Ambiental. Brasília, Universa, 2000.

FIGUEIREDO, C.A.; GONDIM, F.I.D.; LIMA, J.F.; COSTA, S.G.C. Fitoterapia como prática popular em duas comunidades da cidade de João Pessoa Paraíba. Anais do V Colóquio Internacional Paulo Freire, Recife, 2005.

FONSECA-KRUEL, V.S.; PEIXOTO, A.L. Etnobotânica na Reserva Extrativista Marinha de Arraial do Cabo, RJ, Brasil. Acta Botanica Brasilica. São Paulo, v.18, n.1, p.177-190, 2004.

FONSECA-KRUEL, V.S.; PEIXOTO, A.L.; SÁ, C.F.C.; ARAÚJO, D.S.D.; SILVA, W L.; FERREIRA, A.J. Plantas úteis da restinga: $O$ saber dos pescadores artesanais de Arraial do Cabo. Rio de Janeiro, Instituto de Pesquisas Jardim Botânico do Rio de Janeiro, 2006.

GUIMARÃES, M. A dimensão ambiental na educação. Campinas, Papirus, 1995.

LUZZI, D. A 'ambientalização' da educação formal. Um diálogo aberto na complexidade do campo educativo. In: A complexidade ambiental. Enrique Leff (coord.). São Paulo, Cortez. p.178-216, 2003.

MORIN, E. Introdução ao pensamento complexo. Porto Alegre, Sulina, 2006. 
OLIVEIRA, F.C.; ALBUQUERQUE U.P.; FONSECA-KRUEL, V.S.; HANAZAKI N. Avanços nas pesquisas etnobotânicas no Brasil. Acta Botanica Brasilica, São Paulo, v.23, n.2, p.590-605, 2009.

PATZLAFF, R.G.; PEIXOTO, A.L. A pesquisa em etnobotânica e o retorno do conhecimento sistematizado à comunidade: um assunto complexo. História, Ciências, Saúde - Manguinhos. Rio de Janeiro, v.16, n.1, p. 237-246, 2009.

PAVAN-FRUEHAUF, S. Plantas medicinais de Mata Atlântica: manejo sustentado e amostragem. São Paulo, Annablume, Fapesp, 2000.

PINTO, E.P.P.; AMOROZO, M.C.M.; FURLAN, A. Conhecimento popular sobre plantas medicinais em comunidades rurais mata atlântica - Itacaré, BA, Brasil. Acta Botanica Brasilica, São Paulo, v.20, n.4, p. 751-762, 2006.

POLEZZI, R.C.S.; MOTOMIYA, A.V.A.; NISHI, M.L.M.; SOZA, R.P.; OLIVEIRA V.A. Intercâmbio de Informações entre Universidade-Escola-Comunidade envolvendo uso, cultivo e identificação de plantas medicinais, na Vila Pernambuco, de Cassilândia, MS. Anais do II Congresso Brasileiro de Extensão Universitária. Belo Horizonte/MG, 2004. Disponível em: <http://www.ufmg.br/congrext/Desen/Desen12.pdf> Acesso em: 14 abril 2007.

QUINTEIRO, M.M.C. Etnobotânica aplicada à definição de formas tradicionais de uso, manejo e percepção doe recursos vegetais em Visconde de Mauá: ações conjuntas para etnoconservação florestal da Mata Atlântica. Tese de Doutorado em Ciências Ambientais e Florestais; Instituo de Florestas. Universidade Rural do Rio de Janeiro. 2012.

QUINTEIRO, M.M.C. O uso de recursos vegetais pela comunidade de Visconde de Mauá, APA da Serra da Mantiqueira, como base para elaboração de propostas de manejo sustentável. Dissertação de Mestrado em Ciência Ambiental; Instituto de Geociências. Universidade Federal Fluminense. 2008.

RIOJAS, J. A complexidade ambiental na universidade. In: LEFF, E. (coord.). A complexidade ambiental. São Paulo, Cortez. p. 216-238, 2003. 